\title{
Comparison of Conceptual Awareness of Urban and Rural Primary Teachers about Solo Taxonomy
}

\author{
Muhammad Qasim Ali \\ Ph. D. (Scholar) Bahauddin Zakariya University, Multan, Pakistan \\ Email: qasimvr@yahoo.com \\ Muhammad Zafar Iqbal \\ Ph.D. (Scholar) International Islamic University, Islamabad, Pakistan \\ Mehmood UI Hassan \\ M.Phil (Linguistics), Lecturer in University of Lahore Pakpattan Campus, Pakistan \\ Saeed Ahmad \\ Ph.D (Scholar) Linguistics, The Islamia University of Bahawalpur, Pakistan \\ Zafar Masaud \\ Ph.D. (scholar), Preston University, Islamabad \\ Muhammad Akram \\ M. Phil (Scholar) Linguistics, The Islamia University of Bahawalpur, Pakistan
}

Doi:10.5901/mjss.2015.v6n1s1p394

\section{Abstract}

The purpose of this study is to provide a comprehensive insight into the awareness of teachers about SOLO taxonomy. The present study intends to investigate the three levels of SOLO taxonomy: uni-structural level, multi-structural level, relational level. Specifically, the study would like to target the primary school teachers (PSTs) of Punjab province. The participants were the primary school teachers from district Vehari. Descriptive survey research was used in the study. As many as 200 primary teachers were taken as sample. It was found that urban primary school teachers have more awareness about the levels of SOLO taxonomy than the rural primary school teachers. It recommends that both urban as well as rural primary teachers may educate regarding relational level of SOLO taxonomy. It also recommends that Directorate of Staff Development (DSD) may hire professional people who educate urban and rural primary school teachers about the levels of SOLO taxonomy.

Keywords: SOLO taxonomy, awareness, primary teachers

\section{Introduction}

For the effectiveness of SOLO taxonomy, the pedagogical and curriculum objectives must be explicitly stated and clearly spelled out to both teachers and learners. The teaching and learning process including the assessment tasks must be designed with reference to the complexity of understanding with the course objectives. SOLO can be applied to a variety of subjects, from poetry to mathematics (Biggs \& Collis, 1986). Research studies have shown that the SOLO taxonomy is useful in a number of disciplines with teachers' competencies to understand the concept of SOLO taxonomy.

Pedagogy skills and professional efficient knowledge is necessary for a teacher and especially for an elementary teacher to the current need of educational system of a country. The above mentioned factors prove helping hand in students' learning process. Tran and Lawson (2007) described that the prior knowledge that teacher bring to performance for study task within the classroom environment includes not only knowledge in subject-matter but also knowledge in 
teaching and learning area. Therefore, there is a dire need for teachers to upgrade their subject knowledge as well as teaching methodologies.

The present research proposes the development and perception of elementary teachers about SOLO taxonomy in Punjab. The aim of the study is to investigate the understanding of elementary teachers about the most working levels (e.g. uni-structural level, multi-structural level and relational level) of SOLO taxonomy. So, the importance of teacher quality and quality teaching for equipping students sufficiently to meet the constantly changing demands of the contemporary workplace (Macklin, 2006). The present world of experiences requires responses from increasingly skilled teachers, especially high quality of teaching and learning process.

\subsection{Objectives}

This study was guided by following objectives:

- To study the conceptual awareness about uni-structural level of SOLO taxonomy among primary school teachers.

- To find out the conceptual awareness about multi-structural level of SOLO taxonomy among primary school teachers.

- To explore the conceptual awareness about relational level of SOLO taxonomy among primary school teachers.

\section{Literature Review}

Conceptual awareness refers understanding of some field of enquiry pertaining to knowledge of something. Usually professional teachers attempt to develop a sense of important learning and teaching skills. In other words, the concept of conceptual awareness can be explained that it is an ability to find the good stuff in the midst of all of the things that are just filler. Therefore, it is influential and significant that teachers must continue to learn and to be trained well (Saeed, 2011), especially the elementary teachers. That's because they lay the foundation of the nation on solid grounds.

Killen and Hattingh (2004) reported in their study that Structure of Observed Learning Outcome (SOLO) taxonomy make the teachers able to make deduce the things about the understanding of students toward i.e. subjects. Elementary teachers, especially primary school teachers use SOLO taxonomy in planning to recognize, describe, and create learning outcomes and learning experiences. They use it to make assessment for learning at different levels of cognitive intricacy to meet the coherence and high expectations in the curriculum developmental objectives and standards.

Collis \& Biggs (1986) narrates that SOLO taxonomy is a model that makes the elementary teachers to focus on students' understanding and learning against the idea about their cramming regarding things related to their study. Same like their students, teachers come up that SOLO elucidates their inquest into informative teaching practice, supporting them to regulate, monitor, and reveal the efficacy of their teaching. As a result, they produce more effective feedback in prompting next steps for learning. In education, learning taxonomies and frameworks are educational researchers' and theorists' attempts to categorize and make clear learning and learning process (Anderson et al., 2000).

Informed by the work of Biggs (2003) that "SOLO taxonomy describes a series where each partial construction level becomes a foundation on which further learning is built". SOLO taxonomy would pull together the potential to understand the knowledge in teachers and students especially primary teachers. Prakash, Narayan and Sethuraman (2010) narrates that students were inclined to understand how their responses would be graded. Students ardent to use their knowledge of SOLO taxonomy toward being able to better prepare for expressive responses.

The better understanding through (SOLO taxonomy) focuses mainly on construction of knowledge in a congruent way. Its shorthand labels for its diverse levels of student learning outcomes articulates increasingly more advanced understandings of structure (Tan, 2007) that are:

- Pre-structural - lack of structure or inability of subject matter

- uni-structural - single dimension of structure

- multi-structural - multiple structures

- relational - integrated set of structures

- extended abstract - understanding beyond set of structures 


\subsection{Pre-structural level}

There is opening preparation at pre-structural level. The answer indicates lack of ability to engage the question in a meaningful way. At the pre-structural level, understanding of the student attacks the task incongruously. They may collect information but it has no organization or connection with the task and may be irrelevant. This level shows that students did not comprehend the task or what was expected of them (Thompson, 2007). Such a response may involve restating the statement or question, or concentrating on some irrelevant data that is supplementary to the question. It may reproduce the idea that the student is incapable of responding. He does not wish to respond, in the target mode.

\subsection{Uni-structural level}

According to the study of Thompson (2007) the student showed some understanding but was operating an inadequate level to be able to participate in classroom environment. So, this category was considered as contributory fail ' $D$ grade' level. In other words, this level did not give the student the complete understanding toward the task. The reason for a student's responses to be graded in this category was that they had focused only on one aspect of the assessment.

\subsection{Multi-structural level}

The student at this level can use multiple data elements, but the elements are not united into a whole. Hence, the response of the student can consist of a number of distinct closures. Distinctive responses of students would be the following of strict algorithmic procedures that involve a number of steps (Killen \& Hattingh, 2004). However, a single step in the level was forgotten or an error made, the student would be unable to reconstruct the algorithm. Common verbs for multi-structural level are as: enumerate, express, combine, describe, classify.

\subsection{Relational level}

In contrast to a multi-structural response, a relational response reflects the ability to combine the elements into a whole and operations of the questions in a way that enables an overview of the stimulus item in the task. According to Killen and Hattingh (2004) a relational response builds on the multi-structural response by using a previously learnt concept to integrate the ideas.

\subsection{Extended abstract level}

The very last and concluding level of SOLO taxonomy belongs to the deep learning. According to Jimoyiannis (2011) in this highest level of SOLO taxonomy, the student response goes beyond the certain problem to be solved, and patch up the problem to a broader context. The student isable to draws general cases from the specific cases, to develop higher order doctrine and extend the topic to wider application areas in the live setting. At Extended Abstract level, the indicative verbs are: predicate, generate, reflect, debate and generalize. There is a concept generate at extended abstract level that understanding is transferable and generalizable to different areas.

\section{Methodology}

This paper based on descriptive survey research. Study was conducted at district Vehari in Province of Punjab, Pakistan. The sample of the study comprised of 200 elementary teachers. Random sample selection technique was used to select the sample. Data was collected through questionnaire. The questionnaire was validated by the experts and the reliability of the instrument was 0.75 Alpha. Informed consent was taken and respondents were thoroughly briefed about the procedure of filling the questionnaire. Moreover, prior permission was got from District Education Officer, Elementary of district Vehari to collect data. The collected data was thoroughly checked and put into sequence, tabulated and was analyzed.

\section{Analysis and Interpretations of the Data}

The collected data was put into sequence, tabulated and was analyzed. Essential comments and explanations were made. 
Table 1. Mean Standard Deviation and t-value of urban and rural teachers' awareness about uni-structural level

\begin{tabular}{ccccccc}
\hline Item No. & Respondents & $\boldsymbol{N}$ & Mean & SD & t-value & $\boldsymbol{P}$ \\
\hline \multirow{2}{*}{1} & Urban & 120 & 47 & 43.81 & \multirow{2}{*}{0.416} & \multirow{2}{*}{1.960} \\
& Rural & 80 & 19 & 23.28 & & \\
4 & Urban & 120 & 40.25 & 13.55 & 0.416 & \multirow{2}{*}{1.960} \\
& Rural & 80 & 29.6 & 13.01 & & \\
7 & Urban & 120 & 47.5 & 44.78 & 0.341 & \multirow{2}{*}{1.960} \\
\multirow{2}{*}{10} & Rural & 80 & 22.5 & 18.41 & & \\
& Urban & 120 & 40.5 & 36.81 & 0.510 & \multirow{2}{*}{1.960} \\
\multirow{2}{*}{13} & Rural & 80 & 21 & 14.64 & & \\
& Urban & 120 & 47 & 42.59 & 0.392 & \multirow{2}{*}{1.960} \\
\hline
\end{tabular}

Table 1 indicates that the calculated t-value was found to be $(0.416,0.416,0.341,0.510$ and 0.392$)$ at 0.05 levels which are less than the table value 1.960. Hence, urban teachers' ( $N=120, X=47,40.25,47.5,40.5,47, S D=43.81,13.55$, $44.78,36.81,42.59)$ awareness about uni-structural level is better and higher than rural teachers' $(N=80, X=19,29.6$, $22.5,21,19.4, \mathrm{SD}=23.28,13.01,18.41,14.64,25.18)$.

Table 2. Mean, Standard Deviation and t-value of urban and rural teachers' awareness about multi-structural level

\begin{tabular}{ccccccc}
\hline Item No. & Respondents & $\boldsymbol{N}$ & Mean & SD & t-value & $\boldsymbol{P}$ \\
\hline \multirow{2}{*}{2} & Urban & 120 & 48.5 & 44.13 & \multirow{2}{*}{0.988} & \multirow{2}{*}{1.960} \\
& Rural & 80 & 38.8 & 44.51 & & \\
\multirow{2}{*}{5} & Urban & 120 & 39.5 & 27.21 & 0.963 & \multirow{2}{*}{1.960} \\
& Rural & 80 & 35.2 & 26.89 & & \\
\multirow{2}{*}{8} & Urban & 120 & 48.25 & 28.35 & 0.806 & \multirow{2}{*}{1.960} \\
& Rural & 80 & 42.5 & 34.87 & & \\
\multirow{2}{*}{11} & Urban & 120 & 41.5 & 33.70 & \multirow{2}{*}{0.992} & \multirow{2}{*}{1.960} \\
& Rural & 80 & 35.6 & 33.61 & & \\
\multirow{2}{*}{14} & Urban & 120 & 37.5 & 31.09 & 0.860 & \multirow{2}{*}{1.960} \\
& Rural & 80 & 38.6 & 28.01 & & \\
\hline
\end{tabular}

Table 2 reflects that the calculated t-value was found to be $(0.988,0.963,0.806,0.992$ and 0.860$)$ at 0.05 levels which are less than the table value 1.960. Hence, urban teachers' $(N=120, X=48.5,39.5,48.25,41.5,37.5, S D=44.13$, $27.21,28.35,33.70,31.09)$ awareness about multi-structural level is better and higher than rural teachers' $(N=80, X=$ $38.8,35.2,42.5,35.6,38.6, \mathrm{SD}=44.51,26.89,34.87,33.61,28.01)$.

Table 3. Mean, Standard Deviation and t-value of urban and rural teachers' awareness aboutrelational level

\begin{tabular}{ccccccc}
\hline Item No. & Respondents & $\boldsymbol{N}$ & Mean & SD & t-value & $\boldsymbol{P}$ \\
\hline \multirow{2}{*}{3} & Urban & 120 & 29.25 & 18.88 & \multirow{2}{*}{0.854} & \multirow{2}{*}{1.960} \\
& Rural & 80 & 35.6 & 17.84 & & \\
6 & Urban & 120 & 30.25 & 22.77 & 0.890 & 1.960 \\
& Rural & 80 & 37.2 & 26.12 & & \\
9 & Urban & 120 & 28.75 & 21.92 & 0.954 & 1.960 \\
\multirow{2}{*}{12} & Rural & 80 & 37.8 & 20.77 & & \\
& Urban & 120 & 27.5 & 20.76 & 0.931 & \multirow{2}{*}{1.960} \\
15 & Rural & 80 & 35.4 & 21.89 & & \\
& Urban & 120 & 28.5 & 17.54 & 0.945 & \multirow{2}{*}{1.960} \\
\hline
\end{tabular}

Table 3 reveals that the calculated t-value was found to be $(0.854,0.954$ and 0.931$)$ at 0.05 levels which are less than the table value 1.960. Hence, urban teachers' $(N=120, X=29.25,28.75,27.5$, and $S D=18.88,21.92,20.76$, ) awareness about multi-structural level is better and higher than rural teachers' $(\mathrm{N}=80, \mathrm{X}=35.6,37.2,37.8,35.4$ and $\mathrm{SD}=17.84$, 20.77, 21.89). Item no 6 and 15 have the calculated t-value $(0.890$ and 0.945$)$ at 0.05 levels that are less than the table value 1.960. So, rural teachers' $(N=80, X=37.2$ and $35.4, S D=26.12$ and 18.36 ) awareness about multi-structural level 
is higher than the urban teachers' $(N=120, X=30.25$ and $28.5, S D=22.77$ and 17.54$)$.

\section{Discussion}

The basic objectives of the study were to explore the conceptual awareness of primary school teachers about SOLO taxonomy. The findings of this study support that primary teachers have awareness about SOLO taxonomy to some extent. These findings lend support from the findings by Kiani (2011) reported teachers were frequently using the new system of examination SOLO taxonomy in the classroom.

The findings from this study indicate that teachers have awareness about the levels of SOLO taxonomy: Unistructural level, multi-structural level and relational level. These results provide support from the earlier study of Padiotis and Mikropoulos (2010) that through the levels of SOLO taxonomy students construct knowledge and decreased their ambiguities. Further they justified the concept that levels of SOLO taxonomy developed skills of a superior level that are essential for the performance of complex tasks.

Findings from this study show that teachers were conceptually aware about the uni-structural, multi-structural level and relational level of SOLO taxonomy to great extent. Prakash, Narayan \&Sethuraman (2010) reported that the practical value of knowledge of SOLO taxonomy is that it indicates to students the need to improve multi-structural level to relational level responses, wherever the question invites it.

On the other hand, the teachers have awareness regarding the levels of SOLO taxonomy: Uni-structural, multistructural and relational level to great extent. Killen and Hattingh (2004) found that use of SOLO taxonomy opens up a dialogue between teachers and students and places a clear focus on quality learning.

The present study was conducted at district level and the population of the study comprised all the primary teachers of government institutions. The sample was consist only 200 primary teachers. The study may be replicated in other districts and provinces with larger population to get more valid and reliable results for the perception of teachers about the levels of SOLO taxonomy.

\section{Findings and Conclusions}

On the basis of data analysis following findings and conclusion are drawn.

1. It was found that calculated t-value of urban and rural primary teachers were 0.416 at 0.05 levels, 0.416 at 0.05 levels, 0.341 at 0.05 levels, 0.510 at 0.05 and 0.392 at 0.05 levels respectively which were less than the table value. It means that urban primary teachers have conceptual awareness about the uni-structural level of SOLO taxonomy.

2. It was also found that calculated t-value of urban and rural primary teachers were 0.988 at 0.05 levels, 0.963 at 0.05 levels, 0.806 at 0.05 levels, 0.922 at 0.05 levels and 0.860 at 0.05 levels respectively which were less than the table value. It means that urban primary teachers have awareness about multi-structural level of SOLO taxonomy.

3. It was found that means score of the result shows that rural primary teachers are aware than the urban primary teachers. It was found that the mean score of rural primary teachers' $(35.6,37.2 .37 .8,35.4,35.4)$ and urban primary teachers' $(29.25,30.25,28.75,27.5,28.5)$ are respectively. It can be concluded that rural primary teachers were better aware than the urban primary teachers.

4. The results of this study show that majority of the urban teachers have awareness toward uni-structural level, multi-structural level of SOLO taxonomy as compared to rural primary teachers. Whereas majority of rural primary teachers have awareness about relational level of SOLO taxonomy as compared to urban teachers.

\section{Recommendations}

On the basis of findings and conclusions following recommendations are put forward:

1. Majority of the urban primary teachers are aware regarding the uni-structural level of SOLO taxonomy. Therefore, it may recommend that rural primary teachers' may educate about uni-structural level of SOLO taxonomy.

2. It recommends that rural primary teachers may educate regarding multi-structural level of SOLO taxonomy.

3. It may also recommend that there is a need to educate urban primary teachers regarding relational level of SOLO taxonomy.

4. It mayhighly recommend that Directorate of Staff Development (DSD) may hire professional people who 
educate urban and rural primary teachers about the levels of SOLO taxonomy.

5. It may significantly recommend that primary teachers may provide with the material about levels of SOLO taxonomy related to the contents of the syllabus.

\section{References}

Anderson, L. W., Krathwohl, D. R., Airasian, P. W., Cruikshank, K. A., Mayer, R. E., Pintrich, P. R., Raths, J., \&Wittrock, M. C. (2000).A taxonomy for learning, teaching, and assessing: A revision of Bloom's taxonomy of educational objectives. New York:Pearson, Allyn\& Bacon.

Biggs, J. B. (2003). Teaching for quality learning at university. Maidenhead: Open University Press.

Biggs, J. B., \& Collis, K.F. (1986). Evaluating the quality of learning-the SOLO taxonomy.New York: Academic Press.

Jimoyiannis, A. (2011). Using SOLO taxonomy to explore students' mental models of the programming variable and the assignment statement. Themes in Science \& Technology Education, 4 (2), 53-74.

Killen, R., \& Hattingh, S. A. (2004). A theoretical framework for measuring the quality of student learning in outcome-based education. SAJHE, 18(1), 72-86.

Macklin, J. (2006). Teaching standards: Recognising and rewarding quality teaching in public schools. Australian Labor Party.

Prakash, E. S., Narayan, K. A., \& Sethuraman, K. R. (2010). Student perceptions regarding the usefulness of explicit discussion of "Structure of the Observed Learning Outcome" taxonomy. Advances in Physiology Education, 34, 145-149.

Saeed, F. (2011). Developing a rectification taxonomy module for error analysis. 1-152. Pakistan: Allama Iqbal Open University, Islamabad. Retrieved from http://theses.aiou.edu.pk/jspui/handle/123456789/3436

Tan, K. H. K. (2007). Is teach less, learn more a quantitative or qualitative idea? Proceedings of the Redesigning Pedagogy: Culture, Knowledge and Understanding Conference, (pp. 1-17). Singapore.

Thompson, E. (2007, January). Holistic assessment criteria - Applying SOLO to programming project. 66 . Australia: Conferences in Research in Practice in information Technology.

Tran, T. A. \& Lawson, M. (2007).Students' pedagogical knowledge about teachers' use of questions. Internaltional Education Journal, 8 (2), 418-432.

\section{Annexure-1}

\begin{tabular}{|c|l|l|l|l|}
\hline Item No. & Statements & Uni-structural & Multi-structural & relational \\
\hline 1 & How many seasons in a year? & & & \\
\hline 2 & What are the names of the seasons? & & & \\
\hline 3 & In which season do flower blossom? & & & \\
\hline 4 & What is the advantage of playing games? & & & \\
\hline 5 & What do we feel after playing a game? & & & \\
\hline 6 & What we can forget by playing games? & & & \\
\hline 7 & How many brothers in the poem, "The Quarrel"? & & & \\
\hline 8 & How was the start of the poem, "The Quarrel"? & & & \\
\hline 9 & Who quarrel with me and why? & & & \\
\hline 10 & What is the poem, "The Wind" about? & & & \\
\hline 11 & Who has seen the wind? & & & \\
\hline 12 & When do we feel wind is passing by? & & & \\
\hline 13 & Who were there in Anarkali? & & & \\
\hline 14 & Why were the people there? & & & \\
\hline 15 & What did mother buy? & & & \\
\hline
\end{tabular}

